\title{
Корпоративное управление
}

УДК 338.1

\section{Совершенствование управления промышленными предприятиями}

\author{
(C) 2012 2. В.В. Коршунов ${ }^{*}$
}

Решение большинства проблем, стоящих перед организацией, приобретает вид оптимизационной задачи, когда из множества имеющихся альтернатив решения того или иного вопроса выбирается оптимальный вариант, обеспечивающий достижение поставленной цели. Неоднозначность решения проблем, возникающих в процессе управления, требует соответствующего механизма их преодоления, с помощью которого обеспечиваются динамизм и слаженность работы. Механизм управления предприятием предназначен для разработки и реализации системы мер, обеспечивающих необходимые условия эффективного функционирования предприятия. Технические, организационные и экономические меры должны обеспечить синхронность и последовательность режима работы всех составляющих звеньев единой хозяйственной системы на всех уровнях производства и управления для достижения поставленной цели. Важнейшие направления совершенствования управления производством - постановка стратегических целей, разработка программ их реализации, построение моделей развития.

Модели нужны для того, чтобы определить способы достижения цели, выбрать критерии оценки и предсказать последствия заданных способов и форм воздействия на объект управления.

Механизм управления предприятием включает следующие компоненты:

- цели и задачи, стоящие перед управляемым объектом; ничения;

- юридические и экономические законы и огра-

- функциональную структуру органов управления;

- методы и инструменты хозяйственного управления

- методы, правила, средства обработки и передачи информации;

- управленческие решения;

- объекты управления.

Канд. экон. наук, доц. каф. экономической теории НИТУ «МИСиС».
Его назначение - воздействовать на формирование и использование производственных ресурсов, обеспечивая совершенствование технологии и техники производства, разработку, освоение и внедрение новшеств, интенсификацию и повышение эффективности производства, социальное развитие предприятия. Схема механизма хозяйственного управления предприятием представлена на рисунке.

\section{Схема механизма хозяйственного управления предприятием}

Организационная структура управления предприятием соответствует структуре самого предприятия, масштабам и функциональному назначению управляемых объектов. Назначение органов управления предприятием - обеспечить взаимодействие организацию связей и отношений между подразделениями предприятия.

Рыночная устойчивость предпринимательских структур определяется их способностью осуществлять целенаправленную деятельность в условиях конкурентной среды, создавать экономику, основанную на знаниях и информации. Совершенствование системы органов управления связано с решением проблем по двум основным направлениям:

- формирование управляющей системы;

- обеспечение эффективного функционирования системы управления.

Первая группа проблем связана с организацией структуры управления, определением функций структурных подразделений системы управления, разработкой системы информационного обеспечения. Поскольку цель управления состоит в обеспечении решения стоящих перед предприятием задач, проектирование структуры должно основываться на стратегических планах.

Вторая группа проблем связана с организацией процесса управления. Чтобы предприятие успешно функционировало, организационная структура системы управления состоит из органов управления протекающими процессами и органов управления предприятием в целом. Центральный орган, управляющий предприятием, в лице директора и его заместите- 


\section{Цели и задачи, стоящие перед объектом управления}

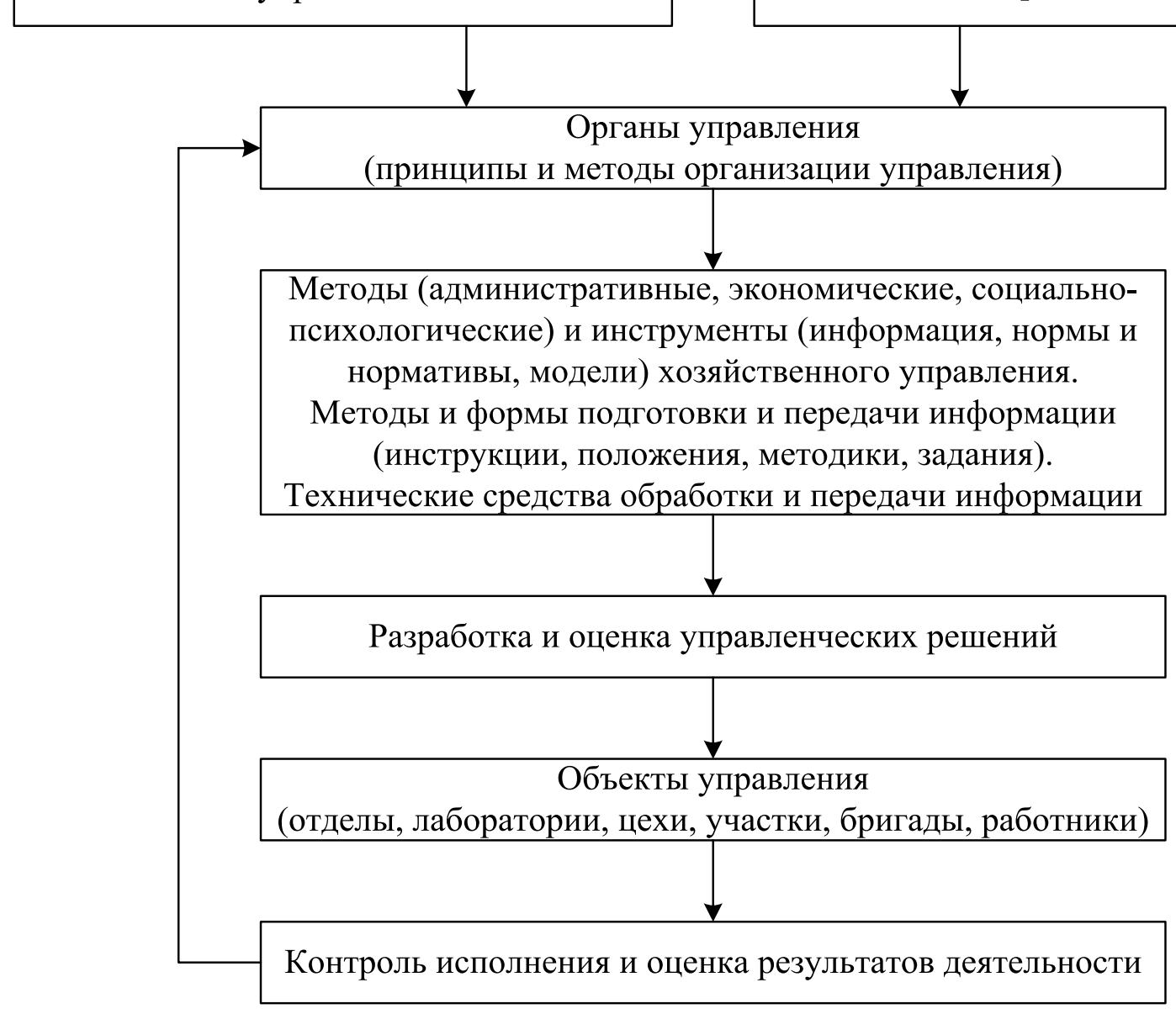

Юридические и экономические законы и ограничения лей концентрирует внимание на конечном целевом результате. Контроль и регулирование промежуточных результатов, направленных на недопущение отклонений в рабочих процессах от установленных заданий, поручаются руководителям и специалистам нижних звеньев предприятия. Управление протекающими в подразделениях предприятия процессами выполняют сами подразделения.

Организационная структура управления внутри предприятия носит в основном ступенчатый характер и строится по принципу подчинения нижестоящего органа вышестоящему. В многоуровневой системе управления необходимо четкое взаимодействие различных звеньев и уровней системы управления. Рациональность подхода к построению организационной структуры управления требует соблюдения следующего правила: взаимоотношения между подразделениями строятся в такой форме, которая позволит достичь целей организации с минимальными издержками.

Направления по организации хозяйственной деятельности могут быть объединены в следующие блоки:
- определение стратегических целей развития предприятий с учетом конъюнктуры рынка и возможности обеспечения производства ресурсами;

- установление задач по реализации целей развития предприятия;

- информационное обеспечение хозяйственной деятельности;

- заключение договоров, разработка производственной программы, определение лимита затрат;

- оперативное управление производством;

- контроль результатов хозяйственной деятельности, их оценка и корректировка задач на последующий период.

Представление о деятельности, достигнутом уровне развития и желательном состоянии предприятия определяют пять компонентов: миссия, стратегия, цели, задачи, действия.

Миссия предприятия - совокупность общих установок и принципов, определяющих предназначение и роль организации в обществе, взаимоотношения с другими социально-экономическими субъектами. Миссия бизнеса состоит в решении проблем потребителя. Функции бизнеса обусловлены потреб- 
ностями общества, которые определяют направления воздействия на процессы воспроизводства. Следовательно, главное назначение предпринимательства - создание потребителя.

Экономическое развитие предприятия обеспечивают процедуры поиска новых технических и организационных решений, ориентированных на достижение новых производственных результатов в борьбе за потребителя с целью повышения устойчивости хозяйственной организации в конкурентной борьбе с другими производителями и увеличения прибыли. Перспективы развития предприятия определяются при разработке экономической стратегии, позволяющей организации адаптироваться к изменениям внешней среды. Стратегия - это комплексный план управления, который должен обеспечить координацию усилий по укреплению положения организации на рынке, успешную конкуренцию, достижение глобальных целей развития. Процесс выработки стратегии основывается на изучении возможных направлений развития деятельности и заключается в выборе общего направления, обслуживаемых потребностей, осваиваемых рынков, привлекаемых ресурсов, методов конкуренции и ведения бизнеса.

Экономическая стратегия определяет цели фирмы, вырабатывает долговременные, наиболее принципиальные установки, намерения в отношении развития производства товаров и услуг. Цели - это ключевые желаемые результаты, к которым стремится предприятие в своей деятельности. Они определяют критерии, которые используют для оценки развития предприятия [1]. Выбор цели предполагает направление на ее достижение определенной совокупности ресурсов, которыми располагает фирма. Поскольку эти ресурсы всегда ограничены, необходимо определить, достижение каких целей обеспечит наибольшую продуктивность использования этих ресурсов, то есть обеспечит конкурентное преимущество фирмы. Для достижения целей необходимо сформулировать приоритетные задачи, их очередность и последовательность решения.

Общая схема проектирования стратегических решений содержит:

- анализ внешней среды, на основе которого определяются рыночные возможности, угрозы, тенденции и стратегические вопросы;

- внутренний анализ, на основе которого определяются стратегические способности и ресурсы, стратегические преимущества и слабости, стратегические проблемы;

- набор стратегических альтернатив, каждая из которых оптимальна при некотором реально возможном сочетании внешних условий;

- оценку различных стратегий, охватывающую весь спектр показателей, характеризующих деятельность компании;

- конкретный выбор стратегии с оценкой возможных рисков.

Выбор стратегии зависит от множества условий: форм конкурентной борьбы и степени ее жесткости, темпов и характера инфляции, экономической политики правительства, сравнительных преимуществ национальной экономики на мировом рынке и иных внешних факторов, а также внутренних факторов, связанных с возможностями самого предприятия, т.е. его производственными и финансовыми ресурсами. Из возможных вариантов стратегии выбирают тот, который в наибольшей степени соответствует условиям внешней и внутренней среды при выбранном направлении деятельности. На этом заканчивается этап собственно построения общей экономической стратегии. Затем эта стратегия детализируется для определения задач и принципов действий отдельных функциональных подразделений. После этого формируется система реализации стратегии и контроля исполнения принятых решений. Экономическая стратегия фирмы в течение всего периода функционирования ориентирована на поддержание конкурентного преимущества, обеспечение длительной успешной деятельности в постоянно изменяющемся мире. На основе представления о своих возможностях, выявляемых в ходе анализа, особое внимание обращается на области деятельности, в которых предприятие превосходит конкурентов и которые нуждаются в улучшении.

Рассмотрим формирование стратегических целей на примере МХК «ЕвроХим» [2] - крупнейшей российской компании по производству минеральных удобрений, включающей следующие производственные предприятия: ОАО «Невинномысский Азот» (Ставропольский край), ОАО «Новомосковская АК «Азот» (Тульская область), ОАО «Ковдорский ГОК» (Мурманская область), ООО ПГ «Фосфорит» (Ленинградская область), ОАО «ЕвроХим-БМУ» (Краснодарский край), Lifosa AB (Литва).

По объему производства МХК «ЕвроХим» входит в тройку европейских и десятку мировых производителей химических удобрений. Цели, преимущества и проблемы при их достижении приведены в табл. 1.

Формирование стратегической цели компании «ЕвроХим».

Принятая стратегия определяет основные направления развития производства:

- увеличение добычи и поставок фосфатного сырья;

- наращивание мощностей для усиления эффекта экономии за счет масштабов производства;

- повышение рентабельности за счет использования энергосберегающих технологий.

Конкурентные преимущества компании составляют новейшие технологии и эффект от масштаба производства. Выработка стратегии заканчивается выбором путей достижения целей, установлением сроков реализации принимаемых решений и оценкой предполагаемых результатов на конец рассматриваемого периода. Сегодня в условиях удорожания сырьевых и энергетических ресурсов на мировом рынке происходит конкуренция издержек. Поэтому необходимо проведение мероприятий по наращиванию мощностей за счет модернизации производств 


\begin{tabular}{|c|c|c|}
\hline \multirow{2}{*}{\multicolumn{3}{|c|}{ Цель компании }} \\
\hline & & \\
\hline \multicolumn{3}{|c|}{$\begin{array}{l}\text { В ближайшие пять лет войти в число пяти мировых лидеров отрасли по объему производства и величине прибыли, при сохранении кон- } \\
\text { курентных цен на свою продукцию, за счет снижения издержек и углубления вертикальной интеграции. }\end{array}$} \\
\hline Преимущества & \multicolumn{2}{|c|}{ Проблемы } \\
\hline Вертикальная интеграция: & Внешние & Внутренние \\
\hline $\begin{array}{l}\text { - компания объединяет добывающие и перерабатывающие предприятия, } \\
\text { собственную сбытовую сеть в России и странах СНГ, компании по продажам } \\
\text { в Швейцарии, США и Бразилии; }\end{array}$ & \multirow{17}{*}{$\begin{array}{l}\text { Появление новых произ- } \\
\text { водственных мощностей } \\
\text { в зарубежных странах } \\
\text { (например, проекты } \\
\text { Ма'аden в Саудовской } \\
\text { Аравии, Вауоvar } \\
\text { в Бразилии) может } \\
\text { неблагоприятно сказаться } \\
\text { на соотношении спроса } \\
\text { и предложениий и пиве- } \\
\text { сти к уменьшению маржи. }\end{array}$} & \multirow{17}{*}{$\begin{array}{l}\text { Высокие затраты на про- } \\
\text { ведение текущего } \\
\text { ремонта и ограничения } \\
\text { по повышению } \\
\text { эффективности произ- } \\
\text { водства ввиду старения } \\
\text { оборудования. } \\
\text { Высокие издержки } \\
\text { на транспортировку } \\
\text { апатитового концентрата } \\
\text { с ОАО «Ковдорский ГОК» } \\
\text { до «Lіfosa АВ» } \\
\text { и ОАО «ЕвроХим-БМУ». }\end{array}$} \\
\hline - лидерство в производстве азотных и фосфатных удобрений; & & \\
\hline $\begin{array}{l}\text { - устойчивое финансовое положение: компания обладает ресурсами, } \\
\text { достаточными для финансирования программ по производству калийных } \\
\text { удобрений к } 2013 \text { году; }\end{array}$ & & \\
\hline - отлаженная система корпоративного управления и прозрачность деятельности; & & \\
\hline - лучшие в отрасли корпоративные программы социальной ответственности. & & \\
\hline Сильные стороны: & & \\
\hline $\begin{array}{l}\text { - наличие собственного сырья в виде апатита с возможностью добычи открытым } \\
\text { методом и с высоким содержанием Р2О5; }\end{array}$ & & \\
\hline $\begin{array}{l}\text {-близость заводов к морским портам и целевым рынкам (Европа, Россия, } \\
\text { страны СНГ). }\end{array}$ & & \\
\hline $\begin{array}{l}\text { - завод «Lifosa AB» расположен в Литве, являющейся членом EC; следовательно, } \\
\text { при продажах в Европу нет импортных тарифов; }\end{array}$ & & \\
\hline $\begin{array}{l}\text { - отсутствие вредных веществ в апатитовом концентрате (например, кадмия), } \\
\text { что является преимуществом при экспорте сырья и удобрений в Европу. }\end{array}$ & & \\
\hline Возможности: & & \\
\hline - получение доступа к казахской фосфоритной руде, что позволит снять & & \\
\hline ограничения на рост мощностей по производству фосфорных удобрений; & & \\
\hline - есть потенциал по дальнейшему повышению эффективности, в частности & & \\
\hline на ОАО «ЕвроХим-БМУ» г. Белореченск Краснодарского края и ОАО «Фосфорит» & & \\
\hline & & \\
\hline & & \\
\hline
\end{tabular}

и снижению энергоемкости всех предприятий, входящих в компанию.

В частности:

- на предприятиях по производству азотных удобрений ОАО «Невинномысский Азот» И ОАО «Новомосковская АК «Азот»: в производстве аммиака - интенсификация действующих агрегатов с увеличением производительности колонн синтеза на $10 \%$, снижением расхода природного газа на 5 - 7 \%; в производстве карбамида - усовершенствование технологии и создание агрегатов большей мощности при снижении энергоемкости производства [3];

- на предприятии ОАО «Ковдорский ГОК»: в производстве фосфатного сырья - совершенствование технологии, внедрение автоматизированных систем управления технологическими процессами, повышение извлечения, улучшение качества продукции и, что особенно актуально, снижение энергоемкости обогатительного производства;

- на предприятиях по производству фосфатных и сложных удобрений (ООО ПГ «Фосфорит», OАО «ЕвроХим-БМУ», Lifosa AB):

1) повышение концентрации диоксида серы в перерабатываемом газе с 8,5-9 \% до $12 \%$, улучшение герметизации систем трубопроводов, установка высокоэффективных теплообменников для охлаждения крепких кислот, газовых холодильников, снижение энергопотребления и увеличение выхода вторичных энергоресурсов, примене- ние новых видов насадок для абсорбционных башен [4, 5];

2) совершенствование конструкции сернокислотных башен и применение ресурсосберегающих технологий дают использование для изготовления аппаратов новых, более устойчивых к коррозии материалов. Это позволит довести утилизацию тепла до $90 \%$, что на 20 \% выше по сравнению с базовым уровнем [3];

3) получение концентрированной экстракционной фосфорной кислоты при переработке апатитового концентрата путем перевода производства с дигидратного на полугидратный метод. В полугидратном способе переработки апатитового концентрата образуется кислота с более высокой концентрацией $\mathrm{P}_{2} \mathrm{O}_{5}(35-37,5 \%)$ по сравнению с дигидратным способом (27-28,5 \% $\mathrm{P}_{2} \mathrm{O}_{5}$ ), что пропорционально снижает затраты на ее упаривание. Резко сокращаются энергетические расходы, так как понижается расход пара и топлива за счет получения концентрированной фосфорной кислоты (52\% $\left.\mathrm{P}_{2} \mathrm{O}_{5}\right)$, перерабатываемой в фосфатные удобрения;

4) снижению энергоемкости в производстве комплексных удобрений способствует разработка ресурсосберегающей технологии новых типов комплексных удобрений с микроэлементами, а разработка и применение замкнутых водяных и газовых систем позволяют исключить или значительно уменьшить вредные выбросы и снизить потребление свежей воды и воздуха. 
Совершенствование систем управления производственными процессами на всех предприятиях, в том числе использование автоматизированных систем управления, позволит одновременно контролировать большое число параметров, получать полную и своевременную информацию о ходе технологического процесса, оперативно реагировать помощью этих показателей определяются эффективные направления деятельности, осуществляется распределение внутренних ресурсов компании для увеличения финансовых результатов и повышения ценности бизнеса. Описание групп целей предприятий и показателей, характеризующих их реализацию, приведены в табл. 2.

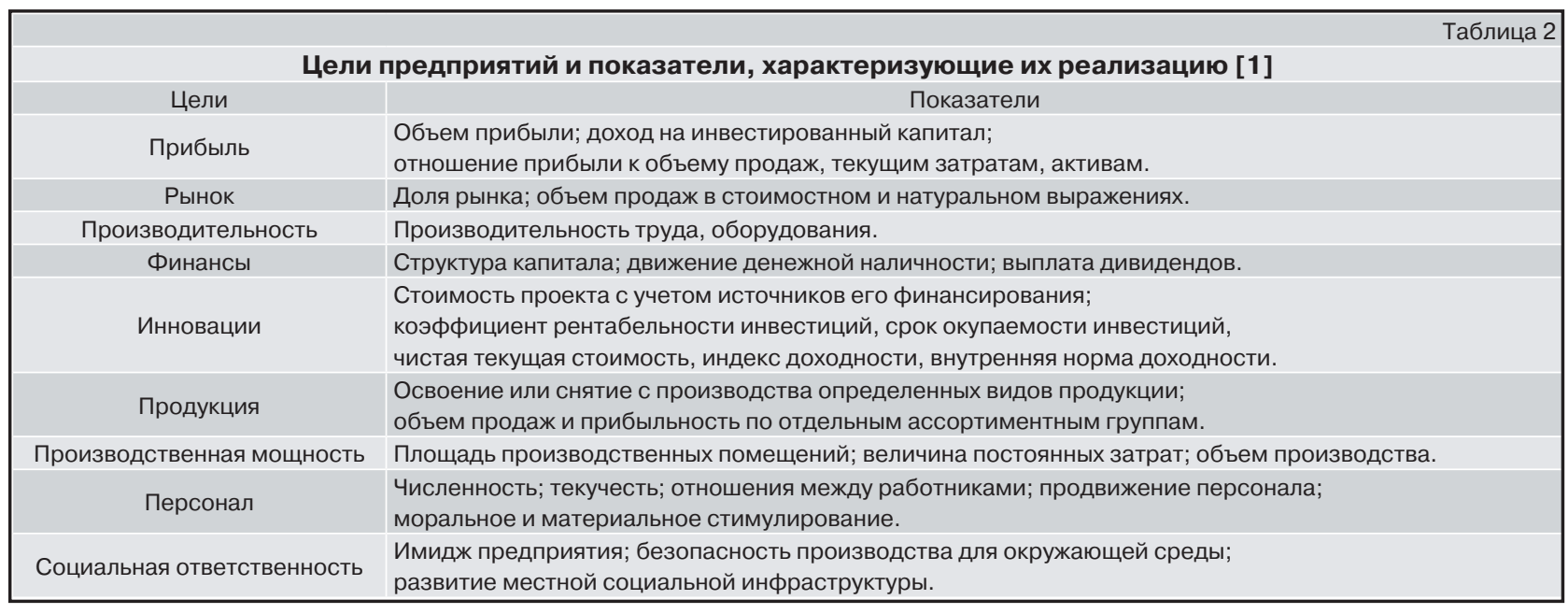

на отступления от заданного режима, уменьшать и даже ликвидировать неритмичность работы, сокращать потери сырья и энергии. Автоматизация производственных процессов, совершенствование систем управления ими позволяют улучшить показатели основных производств: устранить выбросы в атмосферу, увеличить производительность установки, полнее использовать вторичные энергоресурсы и снизить себестоимость продукта.

Мероприятия по внедрению новой технологии предполагают:

- совершенствование на научной основе системы управления и организации производства;

- изменение и улучшение организации труда и подготовки кадров;

- совершенствование системы ценообразования и системы оценок эффективности производства ит.д.

На предприятиях реализацию стратегических целей осуществляют в повседневной деятельности, постоянно проводя технологические и организационные улучшения. Планирование начинается с постановки целей и задач хозяйственной деятельности предприятия, формирования плановых заданий, которые должны быть выполнены в установленные сроки. Определяют способы выполнения заданий: мероприятия и действия людей, движение материальных и финансовых ресурсов, нацеленных на получение конечного результата.

Все параметры деятельности выражаются количественными показателями. Эффективность деятельности компании характеризуют финансовые показатели, такие как рентабельность привлеченного капитала, рентабельность активов и продукции. С
Управление осуществляется на основе регулирования соответствующих показателей, характеризующих состояние управляемого процесса, объекта. В текущей работе предприятия используют так называемые диагностические показатели деятельности, необходимые для обеспечения рационального функционирования, но не связанные с реализацией стратегии напрямую. Эти показатели позволяют контролировать деятельность предприятия и быстро реагировать на возникающие в текущей деятельности проблемы, требующие немедленного решения. Ориентир на показатели деятельности, не влияющие на реализацию стратегии, может привести к использованию ресурсов на выполнение заданий, от которых не зависит достижение общих целей фирмы, т.е. нецелесообразному их расходу.

В настоящее время инвестиции в физические активы осуществляются на основе новшеств. Способность компании мобилизовать и использовать нематериальные активы приобрела большую значимость. Изменения на предприятиях происходят непрерывно. Одна из первоочередных задач совершенствования управления производством в этих условиях - отбор и построение системы необходимых показателей с обоснованием их конкретных уровней. Для этого формируют сбалансированную систему показателей, в которой показатели результатов дополняют показателями процессов, способствующих получению этих результатов. Обе категории показателей увязаны друг с другом, т.к. для достижения результата (например, заданной нормы прибыли на используемый капитал) нужно реализовать процессы (например, добиться определенного прироста продаж, снижения производственных 
затрат за счет проведения технико-организационных мероприятий и т.п.). Реализация перспективного плана происходит посредством включения его частей в текущие планы предприятия, где должны быть приняты решения по составу, содержанию, срокам проведения и ресурсному обеспечению научно-исследовательских и опытно-конструкторских работ; объемам продаж продукции; созданию или перепрофилированию производственных мощностей; подготовке кадров; уровню и структуре издержек; материально-техническому обеспечению производства; источникам финансирования и т.п. Сбалансированная система показателей - это инструмент перевода реализации стратегии непосредственно в повседневную деятельность, который создает возможность координации, повседневного контроля и регулирования руководством хода выполнения стратегического плана.

Процессы экономического развития включают огромное число взаимосвязанных и постоянно меняющихся факторов и получаемых результатов. Окончание одного процесса и достигнутые при этом результаты служат одновременно началом следующего процесса, дающего другие результаты. Так как все экономические процессы, испытывающие одновременное воздействие многих факторов, взаимосвязаны и сдвинуты во времени, оценить место и роль каждого фактора, явления и результата по отдельным частным показателям практически невозможно. Ни один из факторов производства не действует самостоятельно, изолированно и не дает однозначных ответов. Для достижения оптимальных результатов необходима система управления, которая приводит цели сотрудников и подразделений в соответствие со стратегическими целями компании, снижает риск противоречия целей между сотрудниками и подразделениями.

Инструментом, позволяющим связать стратегию с ключевыми бизнес-процессами, является сбалансированная система показателей, а формой представления информации о результатах управления может служить карта сбалансированных показателей. Карта сбалансированных показателей формализует стратегию бизнеса, позволяет детализировать стратегию в частные задания так, чтобы их выполнение приводило к достижению общих целей, обеспечивает мониторинг и обратную связь с отдельными сотрудниками и структурными подразделениями [6].
При разработке карты сбалансированных показателей подбираются те показатели, которые фиксируют этапы выполнения разработанной стратегии при разукрупнении и ранжировании задач стратегического курса и перевода их до уровня текущего управления. Задачи предприятия конкретизируют до уровня повседневных функций, количественных и качественных оперативных заданий подразделениям и персоналу предприятия. Для этого устанавливаются причинно-следственные связи процессов, включаемых в реализацию стратегии. Показатели в системе должны точно отражать процесс или цель, которые оцениваются. Установленные показатели служат ориентиром и позволяют контролировать ход реализации стратегии, обеспечивают обратную связь. Если какой-либо аспект программы выполняется плохо, требуется установить и оценить сущность проблемы и устранить ее. Применение системы сбалансированных показателей позволит управлять процессом реализации стратегических решений непосредственно в процессе повседневной деятельности предприятия.

\section{Библиографический список}

1. Тогузаев T.X. Построение древа стратегических целей развития предприятия и разработка программ их реализации // Экономика и управление. 2010. № 5. С. 115 - 118 .

2. http://www.agrohimtrans.ru/partners/144.html.

3. Левин Б.В. Управление инвестициями и инновациями - приоритетное направление обеспечения конкурентоспособности российских производителей удобрений // Мир серы, N, Р и К. 2004. вып. 4. С. $3-27$.

4. Игин В.В. Опыт работы по реконструкции сернокислотных установок на основе современных энергосберегающих технологий // Мир серы, N, P и К. 2004. вып. 3. С. 9 - 15.

5. Филатов Ю.В., Сущев В.С., Игин В.В., Долгов Д.В. Опыт эксплуатации реконструированных сернокислотных систем на сере с использованием энерготехнологических котлов РКС-95/40 // Мир серы, N, Р и К. 2005. вып. 2. С. 9-17.

6. Бразевич И.С. Формирование системы управления эффективностью деятельности организации // Экономика и управление. 2010. № 5. С. 122 - 124. 